\title{
Unwanted No More: Land Use, Ecosystem Services, and Opportunities for Resilience in Human-In uenced Shrublands
}

\author{
By Mark Brunson
}

\section{On the Ground}

- Shrub-dominated rangelands are highly susceptible to land degradation, partly because low land values can encourage neglect, leading to poor stewardship and/or conversion to more lucrative but ecologically less desirably uses.

- Recent efforts to assess the value of "ecosystem services" show that commodity values don't capture all the benefits of shrublands to society.

- Efforts to prevent shrubland degradation and land type conversion can be enhanced if the value of noncommodity ecosystem services can be recognized.

- Conceptual modeling of socio-ecological systems can point decision makers and stakeholders toward strategies to enhance shrubland resilience and protect ecosystem services.

Keywords: socio-ecological systems, ecosystem services, resilience, shrublands.

Rangelands 36(2):5-11

doi: 10.2111/RANGELANDS-D-13-00064.1

(C) 2014 The Society for Range Management

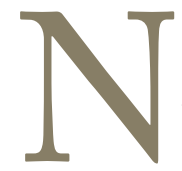

orth American rangelands have never gotten much respect. In the years following the Louisiana Purchase, the US government commissioned teams of explorers to learn exactly what sort of place they'd acquired. One such expedition headed by Major Stephen Long produced a map labeling the Great Plains - the wetter portion of North America's rangelands—as the Great American Desert. In his accompanying report, mapmaker Edwin James wrote of the region:

I do not hesitate in giving the opinion, that it is almost wholly unfit for cultivation, and of course, uninhabitable by a people depending upon agriculture for their subsistence. Although tracts of fertile land considerably extensive are occasionally to be met with, yet the scarcity of wood and water, almost uniformly prevalent, will prove an insuperable obstacle in the way of settling the country (p. 76). ${ }^{1}$

Of course, it wasn't uninhabitable. Before long, pioneer settlers learned how to turn that "desert" into something they valued. Irrigation proved effective for converting rangeland to cropland, although the Dust Bowl proved there were limits to where and how well that approach could succeed. As time went on, other conversions occurred. Cities cropped up in some of the most hospitable locations, often where rivers emerged from the mountains to provide ample water and opportunities for commerce, as in 
Denver, Salt Lake City, and Boise. Other communities sprung up where mineral wealth could be had, although many of those later withered once the mines had played out. By the mid-20th century, some of the driest and most inhospitable locations were chosen as sites for military bases and weapons-testing ranges. Most recently, scenic rangeland areas have become home to "amenity migrants" whose lifestyles and livelihoods allow them to live wherever they choose. Meanwhile, some of the most degraded rangelands also have been converted to residential use. Some conversion has been planned, such as suburban sprawl near cities such as Las Vegas or Phoenix. Other conversions have not, as in the creation of colonias, unincorporated communities in the border states of Texas, New Mexico, Arizona, and California where lands of low agricultural value are divided into small lots with little or no infrastructure and sold to low-income individuals seeking affordable housing.

All of these adaptations by human inhabitants involve conversion of rangelands to something else of greater economic value. Yet rangelands have their own values—-their particular benefits to society- that are often diminished by conversion to other land uses. ${ }^{2}$ To protect and enhance those benefits, range scientists have worked hard for a century to find ways to prevent or reduce degradation, typically by increasing the supply of plants that serve as forage for livestock or wildlife. Even so, restoration of semiarid and arid lands remains difficult and expensive. This is one reason why as much as $20 \%$ of the world's rangelands have been degraded, and why the trend continues at an estimated rate of 30 million acres per year worldwide. ${ }^{3}$ A critical question that faces range managers and policy makers is: How can we slow the trend of degradation and conversion so that their benefits to society and to ecosystems are not lost?

This paper focuses on shrub-dominated rangelands, which are the most prevalent range vegetation type worldwide and which are increasing in proportion relative to grasslands. ${ }^{4}$ Shrublands can be especially susceptible to conversion for several reasons. First, restoration is especially difficult where precipitation is naturally low and/or varies greatly from year to year, and such rangelands tend to be dominated by shrubs rather than grasses or tundra. Second, many shrub-dominated rangelands are degraded grasslands; recovery of their original characteristics would require recrossing an ecological threshold that might be insurmountable. ${ }^{5}$ Third, the values of shrub-dominated systems can be less obvious to society. For example, a recent survey of residents of Montana, Wyoming, and Idaho found that rangelands in a natural shrub-steppe condition were viewed as less scenic than those that had undergone conifer encroachment. ${ }^{6}$ If shrublands are under-appreciated, there is less chance of public pressure to halt conversion to other vegetation types or land uses.

\section{Societal Benefits of Rangelands}

Nearly a quarter century ago, Australian rangeland economists McLeod and Johnston concluded that, except in situations where prescribed burning can achieve the objective, rangeland restoration strategies were rarely cost-effective when judged solely by private economic values. ${ }^{7}$ They suggested that rangeland restoration might be judged worthwhile if a "social benefit-cost analysis" were performed that could incorporate all of the benefits that society would realize from restoration. They also acknowledged numerous reasons why societal benefits were not considered in benefit-cost analyses, including technical problems in valuation as well as a lack of policy mechanisms that could give society a role in restoration.

Rangelands typically have lower real property value than other lands. For example, a 2010 study in Nebraska found that the value of nontillable grazing land was less than $20 \%$ of the value of center pivot-irrigated cropland, and grazing land was valued significantly lower in the drier western portions of the state than elsewhere. ${ }^{8}$ Further, while cropland values were rising at the time, rangeland values were declining. The need to identify societal benefits can be especially acute for shrublands.

In the years since McLeod and Johnston published their paper on the economic costs and benefits of restoring Australian rangelands, a new concept has emerged that can be useful to help identify, understand, and emphasize critical societal benefits of shrublands. The term ecosystem services, defined as "the benefits people obtain from ecosystems," emerged during the 1990s. The idea has taken hold among environmental scientists, government agencies, and nongovernmental organizations worldwide. Economists have so seized on the idea that there is now an entire academic journal called Ecosystem Services. For land managers and decision makers, the concept's chief value is its usefulness for demonstrating how the natural environment affects human health and well-being (Fig. 1). The ecosystem service model proposes four categories of services: supporting services such as nutrient cycling or soil formation, necessary for the production of all other ecosystem services; 


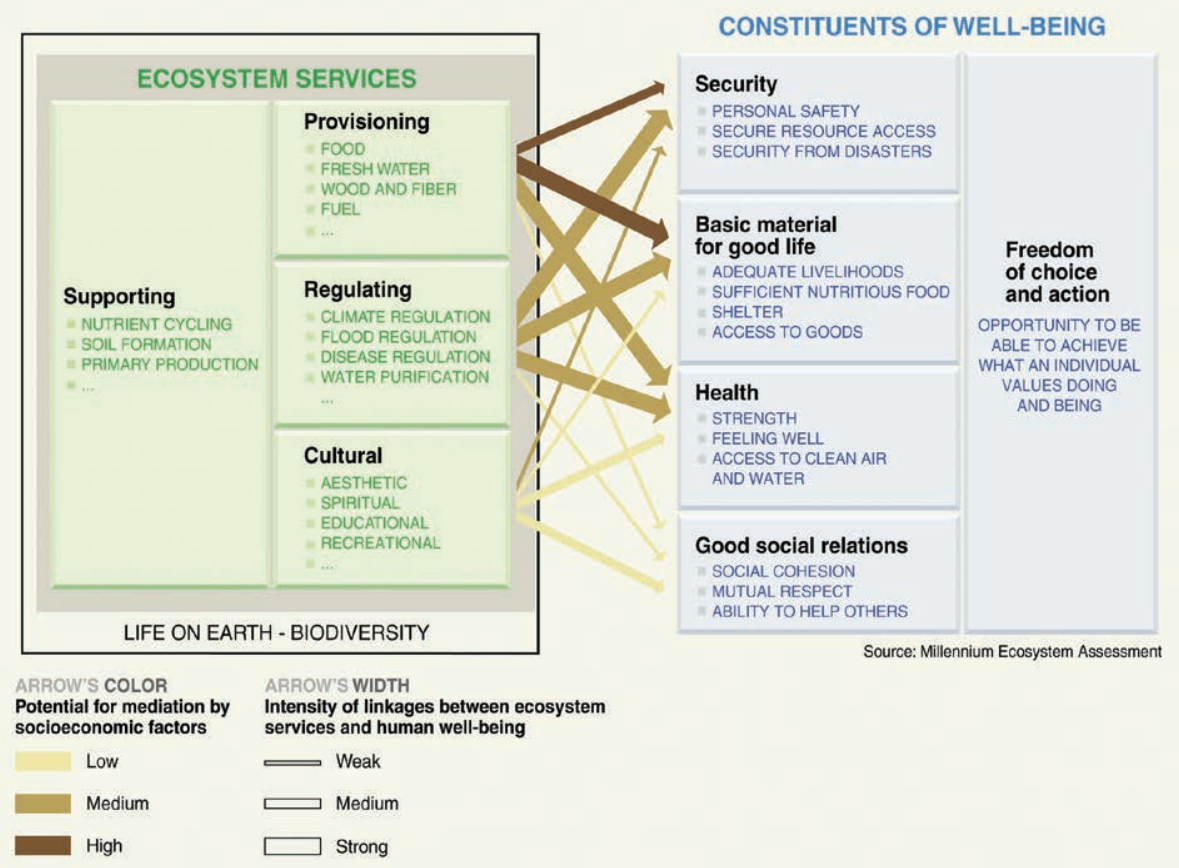

Figure 1. Ecosystem services are the benefits derived from ecosystems. The framework suggests that supporting services such as nutrient cycling or soil formation provide the foundation for three other categories: provisioning services that provide direct benefits to human existence, regulating services that maintain the quality of environments, and cultural services that supply higher-order needs of society. The UN's Millennium Ecosystem Assessment attempted to show how these services might be directly supportive for societal well-being; for example, regulating services such as water purification and disease regulation have a clear connection to human health.

provisioning services, the products obtained from ecosystems such as water, forage, or seed stocks; regulating services, benefits obtained through the regulation of ecosystem processes; and cultural services, nonmaterial benefits such as spiritual renewal or aesthetic and recreational enjoyment. Further, to demonstrate how these services are directly beneficial to humans, the model proposes that these can be linked to specific determinants of human well-being such as security, basic materials to build a good life, health, and good social relations. These, in turn, are said to be the foundational elements of human freedoms of choice.

A second use of the ecosystem services concept is by economists attempting to quantify the real societal value of ecosystems, accounting for those products and services that are bought and sold in markets (for example, timber or livestock) as well as those that markets cannot easily capture such as pollution control or nutrient cycling. These analyses have drawn some skepticism, partly because the calculated values seem unrealistic. For example, an early attempt to synthesize the results of various valuation studies, published in the highly prestigious scientific journal Nature, concluded that the value of the earth's entire biosphere should be estimated at a minimum of $\$ 16-54$ trillion in 1997 dollars. ${ }^{10}$ Considering that the entire global gross national product at the time was about $\$ 18$ trillion, many considered the exercise to be academically interesting but of little or no practical value.

When those calculations were made, the values for rangelands were among the lowest the authors found. They were unable to estimate any value for desert or tundra ecosystems, because no one had yet attempted to calculate those values, and the estimate for total societal value of grass/rangelands was the lowest for any natural ecosystem type, even open oceans. A subsequent Texas A\&M study that based its calculations on the Nature article found that in the San Antonio area, despite a 65\% decrease in the area of rangeland and a $29 \%$ growth in land devoted to urbanized uses that produce substantially less ecosystem services, the total value of those services declined only slightly because there was an increase in the area of woodlands - a conversion that most range scientists define as degradation. ${ }^{11}$ If the ecosystem services model is to be believed - and conceptually it makes sense - then perhaps it is understandable that some shrubland owners seize opportunities to convert rangelands to other land uses, or alternatively overuse or neglect them in ways that degrade them. 
How, then, might the ecosystem service concept be useful in reversing that trend? The possibility lies in the first use of the concept: demonstrating how the natural environment affects human health and well-being. If we seek evidence that such a connection truly exists, we need look no further than the advertisements used to sell private rangelands in the real-estate market, where sellers often emphasize ecosystem services their properties possess. This can be seen in some of the descriptions found in late October 2013 at just one online rural property website (LandWatch.com):

- Supporting and provisioning services near Chetwynd, in northern British Columbia: "2,000 acres suitable for hay/grain or pasture ... This property was once the bottom of a glacial lake and the valley formed has rich silty fertile soil full of natural minerals and marl lime."

- Provisioning and cultural services near Sheridan, Wyoming: “ ... [T] he most uninterrupted and beautiful views of the Big Horn Mountains you will find anywhere. Comes complete with ponds for fishing, and plenty of trophy game like elk, mule deer and white-tail deer, not to mention game birds and many other species from a well-protected natural environment."

- One property-seller even proclaimed value in the degraded shrubland condition of a tract in Ward County, Texas: "The property has sparse vegetation, mostly clump grass and shrubs of mesquite and salt cedar. Most shrubs are about 3-4 feet high, with some as tall as 6 feet. But the shrubs are mostly spread out with plenty of room to walk between them."

These ads illustrate the ecosystem services derived from rangelands, and also highlight the problem: conversion to land uses that capture more of the economic value of those services than can be realized in an undeveloped state, while diminishing those services. Conversion even to exurban subdivisions can have a significant negative impact on biodiversity. ${ }^{12}$ The challenge is to promote those values in a way that encourages conservation and restoration of shrublands rather than converting them to residential or other uses.

\section{Resilient Socio-Ecological Shrubland Systems}

Meeting the challenge will require enhancing the resilience of shrublands so that society can realize greater value from their ecosystem services. This might be better achieved by thinking of shrublands as socio-ecological systems, rather than simply as a type of land. The term "socio-ecological systems" has come into vogue in recent years because scientists recognize that no natural systems exist on earth without human impacts, nor can any social systems exist without nature. Social and ecological systems are not just linked, but are so interconnected that neither can be fully understood without considering the other. This understanding is embodied within the ecosystem services concept.

The concept of ecological resilience now has been expanded to encompass socio-ecological systems. The definitions of ecological and socio-ecological resilience are almost identical. British geographer Neil Adger and colleagues presented a widely used definition of socio-ecological resilience: "the capac- 
ity of linked social and ecological systems to absorb recurrent disturbances ... so as to retain essential structures, processes, and feedbacks."13 Recurrent disturbances might include such familiar events as a wildfire or defoliating insect outbreak, but also creation of new ATV trails or rural subdivisions. Essential structures include streams or dominant shrubs, and also bridges over streams and agencies that manage shrublands. Socio-ecological system processes include succession and nutrient cycling as well as land sales and passage of new legislation. Feedbacks describe how plants influence soils and vice versa, and also how decisions to disturb soil in order to grow new plant varieties can create conditions landowners must address, for example by spraying herbicide on newly invasive weeds.

As yet, few scientists have studied socio-ecological resilience of shrublands, although there have been numerous studies of ecological resilience in Australia, the Mediterranean region, and western North America. One scholar who actively applies the socio-ecological resilience concept to rangelands is Australian range scientist Brian Walker, whose well-written and easily understood books with coauthor David Salt on the concepts and practice of resilience ${ }^{14,15}$ offer multiple examples based on rangeland studies. One concept advanced in their books is to explicitly consider ecosystem services- those that are not captured by private economic markets as well as those that are. Other principles or practices they espouse that can prove beneficial to shrubland resilience include: create opportunities to improve information flow between scientists, land managers, and engaged stakeholders; promote and sustain diversity in various forms (e.g., biological, economic, landscape); and design practices and rules to adapt to variability in the system rather than trying to optimize for stable-state conditions that might not always exist.

\section{Conceptual Modeling for Resilience}

One way to improve information flow is to engage relevant groups (managers, scientists, stakeholders) to jointly develop and test conceptual models of how system components are interconnected - that is, identify the essential structures, processes, and feedbacks that influence a particular set of management goals. Figure 2 depicts a generalized conceptual model of socio-ecological systems, centered on the role of intentional stewardship and policy choices to influence a system's capacity to provide ecosystem services. The model assumes decision makers seek stewardship options that can influence ecosystem patterns and processes in ways that move a site or landscape toward a desired range of ecosystem services. To enhance resilience, participants in model development collaboratively identify factors that can constrain or guide their choices. These include coarse-scale (regional to global) influences that define what is lawful and possible, and local-scale influences that determine the variability of actual ecological and social conditions, and can be used to identify a narrower range of feasible choices based on local conditions, management traditions, and social constraints. It is important also to consider how those different elements are interconnected - for example, how policy shifts might intersect with local management norms, or how climate change could affect local viability of notable plant or animal species.

Once a model is defined, decision makers not only can identify a stewardship strategy that appears to be feasible, but also "leverage points" - influential elements within the larger system that, if adjusted, can make that strategy more effective. If the leverage points are at the coarse scale, then it is likely that a change in policy will be needed; if the leverage points are predominately local-scale, then enhanced learning and/or innovation can offer opportunities to increase resilience.

In US shrublands, coarse-scale influences that set the range of possible options include low rates of nutrient cycling and frequent or prolonged droughts that limit the land's ability to recover from major disturbance. They also include political pressures that make innovations in grazing management difficult to apply on public land, and population trends in fast-growing western rangeland states that increase demand for low-priced land. At the local scale, fire histories affect not only the structure of ecosystems but also how local communities perceive and respond to wildfire risk. Similarly, land-use history affects a shrubland's capacity to recover from disturbance and also how local communities respond to those disturbances. For example, where early efforts at irrigated crop agriculture have failed, local soil conditions can be degraded by plowing or increased salinity, creating local economic conditions that pressure governments to pursue risky development schemes on those degraded lands. Cross-scale connections within the system include federal policies that affect the relative attractiveness of conservation or economic development, or climate change effects on post-disturbance revegetation success. The choice of a stewardship option will depend mainly on these conditions and constraints. 
Leverage points at the coarse scale typically involve a change in policy or budget. For example, increased expenditures on the development of native seed sources could improve revegetation success after wildfires or soil-disturbing activities-especially if accompanied by local innovations in the use of seeding technologies or grazing management (such as increasing use of vacant federal allotments as forage banks to assist livestock producers whose private or public grazing areas are in need of recovery). Also at the local scale, municipal or county policies that require innovations in subdivision design might increase the land's capacity to retain species, while accommodating population growth. Coarse-scale policy adjustments typically are outside a land manager's control, but when multiple stakeholders who have traditionally been in conflict agree on a strategy, policy makers have a tendency to listen more closely than when multiple sides of an issue advocate for different policies.

One advantage of engaging diverse stakeholders in this sort of process is that persons who are familiar with a system for different reasons are likely to notice different aspects of how it functions and has changed over time. Moreover, the experience of reaching a shared goal of collaboratively developing the model can increase trust between seemingly opposed parties. This, in turn, promotes a continued flow of information that helps managers discern more quickly whether a strategy is working or needs to be adjusted. Collaboratively building the model also helps draw attention to the diversity of system components to be maintained, because different participants are likely to focus on different ecosystem services. For example, if there is concern about species diversity and its role in the habitat, hunters might key in on different species than birders or livestock producers. If the modeling exercise seeks to identify variability within the system, there is less temptation to focus on optimizing conditions that promote one particular ecosystem service without considering the effects on other services.

\section{Conclusion}

The process described in this article has not yet been implemented in full, although the idea of using systems modeling as a tool in environmental conflict management has been advanced since the 1990 s. ${ }^{16}$ The merger of systems modeling and resilience thinking is described in case studies provided by Walker and Salt. ${ }^{15}$ This article offers managers and stakeholders a starting point for such an exercise- a way of thinking about a system that is focused particularly on the task of those who care about and/or are responsible for the stewardship of rangelands.

The problem of shrubland degradation is one where there is a clear need for new ways of thinking about conservation and restoration. Shrublands are especially vulnerable to degradation caused by land-use change or neglect. They provide ecosystem services, but those services might not be obvious to much of society, reducing public pressure to protect their diverse values. It is important to recognize that shrubland decline is an environmental problem, but not solely an environmental problem. To address the problem, it is vital to seek to understand environmental and human drivers of decline at multiple scales. Viable solutions will seek to improve both environmental and human conditions at the scale at which the stewardship option is addressed.

\section{References}

1. Meinig, D. W. 1993. The shaping of America: a geographical perspective on 500 years of history. Volume 2: Continental America, 1800-1867. New Haven, CT, USA: Yale University Press. 576 p.

2. Harstad, K. M., D. P. C. Peters, R. Skaggs, J. Brown, B. Bestelmeyer, E. Fredrickson, J. Herrick, AND J. Wright. 2007. Ecological services to and from rangelands of the United States. Ecological Economics 64:261-268.

3. Millennium Ecosystem Assessment. 2005. Ecosystems and human well-being: desertification synthesis. Washington, DC, USA: World Resources Institute. 26 p.

4. Estell, R. E., K. M. Havstad, A. F. Cibils, E. L. Fredrickson, D. M. Anderson, T. S. Schrader, and D. K. JAMEs. 2012. Increasing shrub use by livestock in a world with less grass. Rangeland Ecology E Management 65:553-562.

5. D’Orico, P., G. S. Okin, and B. T. Bestelmeyer. 2011. A synthetic review of feedbacks and drivers of shrub encroachment in arid grasslands. Ecohydrology 5:520-530.

6. Nay, C. G., And M. W. Brunson. 2013. A war of words: do conflict metaphors affect beliefs about "unwanted" plants? Societies 3:158-159.

7. McLeod, N. D., and B. G. Johnston. 1990. An economic framework for the evaluation of rangeland restoration projects. Rangeland Journal 12:40-53. 
8. Johnson, B. B., R. Lukassen, and T. Rosener. 2010. Cropland values rise while rangeland values fall. Cornhusker Economics. Paper 439.4 p.

9. Millennium Ecosystem Assessment. 2003. Ecosystems and human well-being: a framework for assessment. Washington, DC, USA: World Resources Institute. 245 p.

10. Costanza, R., R. d’Arge, R. de Groot, S. Farber, M. Grasso, B. Hannon, K. Limburg, S. Naeem, R. V. O'Neill, J. Paurelo, R. G. Raskin, P. Sutton, and M. van den Belt. 1997. The value of the world's ecosystem services and natural capital. Nature 387:253-260.

11. Kreuter, U. P., H. G. Harris, M. D. Matlock, and R. E. Lacey. 2001. Change in ecosystem service values in the San Antonio area, Texas. Ecological Economics 39:333-346.

12. Hansen, A. J., R. L. Knight, J. M. Marzluff, S. Powell, K. Brown, P. H. Gude, and K. Jones. 2005. Effects of exurban development on biodiversity: patterns, mechanisms, and research needs. Ecological Applications 15:1893-1905.

13. Adger, W. N., T. P. Hughes, C. Folke, S. R. Carpenter, and J. Rockström. 2005. Social-ecological resilience to coastal disasters. Science 309:1036-1039.

14. Walker, B., and D. Salt. 2006. Resilience thinking: sustaining ecosystems and people in a changing world. Washington, DC, USA: Island Press. $174 \mathrm{p}$.

15. Walker, B., AND D. Salt. 2012. Resilience practice: building capacity to absorb disturbance and maintain function. Washington, DC, USA: Island Press. 226 p.

16. Daniels, S. E., and G. B. Walker. 1996. Collaborative learning: improving public deliberation in ecosystembased management. Environmental Impact Assessment Review 16:71-102.

Author is Professor and Department Head, Dept of Environment and Society, Utah State University, Logan, UT84322 (Mark.Brunson@usu.edu). This research was supported by the Utah Agricultural Experiment Station, Utah State University, and approved as journal paper number 8639. 